Fecha de recepción: febrero 2010 Fecha de aceptación: agosto 2010 Versión final: marzo 2011

\section{RSE - Comunicación para el Desarrollo Sostenible en una empresa de servicio básico y social: Caso Aysa}

\author{
Adriana Lauro ${ }^{*}$
}

\begin{abstract}
Resumen: En este artículo la autora comparte un caso líder desarrollado por la empresa proveedora en Argentina de un servicio básico y social como lo es el agua, en el marco de la gestión de Responsabilidad Social Empresaria en el que se introduce un nuevo concepto en la gestión profesional de la comunicación: $\mathrm{CpD}$-Comunicación para el desarrollo-, en un contexto en el que la sociedad va tomando conciencia de que el lenguaje 'construye el mundo'. También, reflexiona acerca de la labor de los comunicadores que ya no sólo es elaborar mensajes apropiados y comunicarlos de manera atractiva. Los profesionales tienen que tener la visión y la capacidad de generar 'significados comunes' y propiciar un proceso de diálogo, negociación y consenso con los públicos, sobre la base de una comunicación de doble vía que den respuestas a lo que la sociedad y los distintos grupos esperan.
\end{abstract}

Palabras claves: Comunicación Corporativa - Comunicación Digital - Comunicación Empresaria - Comunicación Institucional - comunicación para el desarrollo - Dircom - gestión comunicacional - Imagen Corporativa - públicos -Relaciones con la Comunidad - Relaciones Públicas - Reputación Corporativa - Responsabilidad Social Empresaria - Social Media.

[Resúmenes en inglés y portugués y currículum en la página 149]

Para una empresa como $A y S A$, proveedora de los servicios esenciales de agua y saneamiento, la comunicación es fundamental. Esto se debe principalmente al alto nivel de exposición por ser servicios presentes en forma continua en la vida cotidiana y, como contrapartida, por la elevada sensibilidad social que representan estas prestaciones para quienes aún no las tienen.

Así, a lo largo del tiempo, la comunicación ha sido y es un aspecto central en la gestión y ha resultado clave incorporarla en la planificación estratégica de las compañías del sector, ya sean privadas o públicas.

Sin lugar a duda, los '90 han sido un punto de inflexión en la institucionalización y consolidación de áreas específicas con este tema a cargo, las cuales estaban principalmente orientadas a conocer a los clientes / usuarios, mantenerlos informados y generar acciones para establecer o mejorar el vínculo.

En este sentido y en términos generales estas áreas se ocupaban de:

- La identidad corporativa: intervenir integralmente en todos los modos en los que se manifiesta la empresa y proveer el marco normativo para lograr una clara identificación por parte de los 
clientes / usuarios y de la comunidad en su conjunto.

- La investigación de mercado: indagar y monitorear la satisfacción con el servicio para generar acciones de mejora.

- Llevar adelante toda la comunicación masiva e institucional.

- Diseñar las herramientas y los puntos de contacto con los clientes / usuarios.

- Generar acciones de promoción para fidelizar clientes / usuarios y organizar eventos recreativos para el público en general, aumentando la presencia institucional.

Pero las exigencias son cada vez mayores. El contacto diario se ha transformado en una comunicación en tiempo real, vertiginosa y ampliamente documentada por las posibilidades que la tecnología digital le ofrece al público, cualquiera sea su condición económica y social. Este contexto le imprime a la comunicación una dinámica sin precedentes históricos y exige un elevado profesionalismo, precisión conceptual, capacidad técnica y una actitud proactiva. En tal sentido, la anticipación de escenarios resultante del análisis del vasto caudal informativo se torna en elemento clave para el logro de dos objetivos básicos: comunicar en tiempo y forma, y asesorar a la alta dirección de modo simple, preciso y oportuno.

Pero, por otra parte, la sociedad va tomando conciencia de que el lenguaje 'construye el mundo'. Entonces la labor de los comunicadores ya no sólo es elaborar mensajes apropiados y comunicarlos de manera atractiva. Los profesionales tienen que tener la visión y la capacidad de generar 'significados comunes'.

En los últimos años ha habido una evolución en los públicos que esperan no sólo ser receptores sino parte de un proceso de diálogo, negociación y consenso.

Así, hoy, para llevar adelante con éxito proyectos es fundamental promover una comunicación de doble vía, escuchar, consultar, intercambiar conocimientos y fomentar iniciativas coherentes con la realidad y, fundamentalmente, que den respuestas a lo que la sociedad y los distintos grupos esperan.

La experiencia ha demostrado que los proyectos mejor diseñados son los que toman en cuenta lo que piensan y esperan los grupos a quienes van dirigidos, los cuales deben ser consultados, debidamente informados y movilizados.

El potencial de este estilo de comunicación, denominada Comunicación para el Desarrollo, es inmenso para generar verdaderos cambios sociales, reformas sectoriales, promover la participación de la sociedad civil y cobra vital importancia como generadora de consensos y alianzas entre todos los actores involucrados, sobre todo en temas tan trascendentes como la implementación de infraestructuras y la prestación de servicios básicos como los de agua y saneamiento. La Comunicación así entendida tiene un rol estratégico, permite la construcción de una relación centrada en la transparencia, la confianza y la credibilidad. Permite generar cambios de comportamiento para mejorar las condiciones de vida de las personas y garantiza la sostenibilidad de los proyectos.

El nuevo rol de los comunicadores entonces, es colaborar en el tejido de la trama social, constituirse en el facilitador de intercambios para generar una interlocución legítima, a través de la 
cual se garantice que todos los actores tengan voz y sus posiciones sean escuchadas y tenidas en cuenta, como base para el desarrollo y el cambio social.

Por eso, la comunicación debe ser una de las dimensiones constitutivas de los proyectos y no un agregado o una cosmética.

¿Qué es la Comunicación para el desarrollo $(\mathrm{CpD})$ ?

Es el uso planificado de técnicas, actividades y medios de comunicación que permite a las personas realizar cambios y disponer de más capacidad para orientar las decisiones que repercuten en su vida. Un intenso intercambio de ideas entre todos los sectores de la sociedad puede conducir a un mayor compromiso de la población con una causa común, requisito fundamental para lograr un desarrollo sostenible.

(Definición de la Organización de las Naciones Unidas para la Agricultura y la alimentación)

\section{La relación Comunicación - Desarrollo}

En los últimos años se ha reconocido internacionalmente la importancia de la comunicación como un recurso estratégico para los procesos de desarrollo humano sostenible. De allí que internacionalmente se hayan generado varias iniciativas para fortalecer la noción de una Comunicación para el Desarrollo.

Con la intención de fomentar esta visión, la Organización de las Naciones Unidas para la Agricultura y la Alimentación (FAO) viene promoviendo experiencias prácticas, así como la discusión entre actores sociales que trabajan en prioridades del desarrollo sostenible.

La Comunicación para el Desarrollo $(\mathrm{CpD})$ juega un importante rol en el diseño, implementación, monitoreo y evaluación de proyectos -como los programas de agua y saneamiento mencionados-, especialmente en lo concerniente a la creación de un entorno propicio para el diálogo político y público, la consulta y participación de diversos grupos, la construcción de consensos, la gestión y diseminación del conocimiento, la promoción de cambios de actitudes y comportamientos en poblaciones meta, $\mathrm{y}$ el fortalecimiento de procesos de gobernabilidad.

Históricamente, la relación desarrollo - comunicación ha sido estrecha y ambos términos han ido evolucionando conjuntamente: a cada nueva concepción del desarrollo le ha correspondido una manera de entender y practicar la comunicación.

En nuestro continente se ha debatido largamente sobre estos aspectos, desarrollo y comunicación, y su correspondencia. Seguramente esto se deba a las problemáticas de la región, a su misma realidad, la que obliga al análisis y la profundización de estas cuestiones.

Es así que, América Latina ha liderado la investigación a nivel mundial y cuenta con importantes aportes y estudios sobre el tema.

Podemos citar algunos ejemplos tomados del trabajo `Congreso Mundial de Comunicación para el desarrollo ¿Qué comunicación para cuál desarrollo?' realizado por Amparo Cadavid Bringe (2006).

Esta autora menciona a Luís Ramiro Beltrán, pionero estudioso de la comunicación, boliviano, primer premio Mc Luhan - quien, ya en los sesenta, señalaba la importancia central que tiene la comunicación en los proyectos de transformación social. 
También, los trabajos del uruguayo Juan Díaz Bordenave y del argentino Daniel Prieto Castillo, cuyo aporte proviene del trabajo de campo rural y comunitario.

Otro teórico importante, que planteó un cambio fundamental en la concepción de la comunicación es el brasilero Paulo Freire, quien desde la educación cuestionó a fondo el modelo autoritario que concebía la existencia de un sujeto dador de conocimiento y verdad a un receptor, pasivo y dependiente. Esta concepción, generada a comienzos de los setenta, tuvo tanta repercusión en el continente que acabó por influir en la transformación del modelo educativo, y su influencia alcanzó el campo de la comunicación. Estos planteamientos critican al modelo funcionalista de comunicación efectivista basado en la verticalidad del emisor - mensaje / medio - receptor y en la creencia del impacto de este tipo de proceso, mediante el cual se lograría transformar las percepciones y hasta la conducta del receptor.

La otra personalidad mencionada en el escrito, es el uruguayo Mario Kaplún, quien desde la práctica de la radio - educación, también critica este modelo autoritario, que desconoce al receptor como un interlocutor activo con capacidad para generar su propios mensajes, según sus necesidades y su cultura. Kaplún invita a ver en los receptores personas concretas arraigadas en una cultura y en una vida cotidiana que genera sensibilidades, idiosincrasias, mentalidades y actitudes creativas y productivas.

De este modo, pensar la comunicación desde la cultura transforma la mirada de la comunicación y cuestiona los modelos anteriores. En este contexto "el emisor y el receptor se convierten en interlocutores, en sujetos con historia, identidad, arraigo, vidas y experiencias concretas en un marco real, con necesidades y expectativas y capacidad creativa, que pueden (y de hecho así lo hacen) intercambiar para construir algo nuevo que es producto de este intercambio cultural" (Cadavid Bringe, 2006).

\section{Comunicación y desarrollo en políticas de integración. La experiencia de AySA}

El agua y el saneamiento tienen un valor fundamental para cualquier comunidad, tanto a nivel de la salud pública como de su organización social, ya que constituyen una herramienta esencial para la cohesión y para el fortalecimiento del sentido de pertenencia al barrio, a la ciudad y, en definitiva, a la Nación. Entendemos, entonces que, el modo en que se suministran y cómo se los utiliza y valora, forman parte de la cultura de una comunidad y constituyen un aspecto indisociable de su identidad.

En lo referido a la problemática del desarrollo de estos servicios en barrios de bajos recursos, no existía una estrategia definida que contemplara todos los aspectos e involucrara a todos los actores. Por eso, desde hace unos años, se ha iniciado en nuestro país y específicamente en el área de acción de esta empresa ${ }^{1}$, un proceso para modificar esta situación y lograr el beneficio directo de estos sectores, a través de una metodología participativa.

En este contexto, además de resolver los desafíos de infraestructura y las inversiones requeridas para lograr la universalización de la cobertura, fue necesario desarrollar programas, herramientas y mecanismos que faciliten la atención de las necesidades y políticas globales de integración de estas comunidades relegadas. 


\section{La comunicación un aspecto clave durante todo el proceso de expansión de los servicios}

Esta nueva modalidad de gestión hace imprescindible la implementación de procesos de comunicación adecuados, que se adapten a las realidades de los distintos actores involucrados para lograr una participación más activa y comprometida de todos. La solución a la problemática de estos barrios debe provenir del trabajo mancomunado.

En esta línea, AySA trabaja aplicando dos metodologías: el Modelo Participativo de Gestión $(\mathrm{MPG})$ y los planes Agua + Trabajo $(\mathrm{A}+\mathrm{T})$ y Cloaca + Trabajo $(\mathrm{C}+\mathrm{T})$, mediante las cuales se articula el trabajo conjunto de la empresa, la comunidad barrial, los municipios, organismos del Estado y organizaciones sociales.

\section{¿Qué es el Modelo Participativo de Gestión (MPG)?}

Esta metodología se basa en el trabajo compartido y mancomunado de las comunidades barriales, los municipios y la empresa, con el objetivo de lograr el acceso a los servicios de agua potable y desagües cloacales para la población residente en barrios de escasos recursos.

Cada actor tiene su rol:

- AySA aporta la mayor parte del financiamiento de los proyectos, efectúa la supervisión técnica y el acompañamiento social de las obras.

- Los vecinos contribuyen con la mano de obra, para lo cual reciben la capacitación técnica necesaria. Además participan en talleres sobre el buen uso de los servicios y la facturación de los mismos.

- El municipio prioriza los proyectos, aporta materiales y maquinarias, y es responsable de la dirección técnica de los trabajos.

\section{¿Qué son los planes Agua + Trabajo $(\mathrm{A}+\mathrm{T})$ y Cloaca + Trabajo $(\mathrm{C}+\mathrm{T})$ ?}

La concepción de estos planes presenta tres aspectos innovadores: su objetivo, su metodología y su escala.

- Objetivo: estos planes tienen un doble propósito, por un lado, hacer posible que las comunidades de escasos recursos económicos tengan acceso a agua potable por red y/o desagües cloacales, y por otro, generar fuentes de trabajo genuinas y de largo plazo a través de la conformación de Cooperativas de Trabajo.

- Metodología de trabajo: la expansión se realiza a través de la ejecución Módulos. Para agua, obras de aproximadamente 5.000 metros de cañería y 500 conexiones domiciliaras. Para cloaca, obras de 3.000 metros de cañería y 300 conexiones domiciliarias. Lo destacable es la utilización de mano de obra desempleada o proveniente del sector informal, en general poco calificada, que se agrupa en Cooperativas de Trabajo, a las que la empresa capacita para la ejecución. 
- Escala: desde su inicio hasta fines del año 2008, se ejecutaron 274 Módulos, esto significa que se han instalado más de 1.200 kilómetros de cañerías de agua potable y que más de 700.000 personas han sido beneficiadas por el Plan. Los Módulos estaban distribuidos en 12 municipios del área de acción de la empresa: Almirante Brown, Avellaneda, Esteban Echeverría, Ezeiza, Hurlingham, La Matanza, Lanús, Lomas de Zamora, Morón, Quilmes, Tigre y Tres de Febrero. Esta distribución geográfica y su crecimiento respecto del año 2007 -cuando había Módulos en Ejecución sólo en 8 Municipios- son un claro reflejo de la escala que ha alcanzado el Plan.

Mediante ambas metodologías se procura realizar un acompañamiento social de la expansión, que considere los alcances reales que conlleva la incorporación a las prestaciones. Por esa razón, la empresa contempla para el diseño y la ejecución de los proyectos que cada parte pueda aportar sus pareceres, se toman en cuenta las alternativas que surgen de este diálogo y se logre, así, capitalizar diferentes experiencias. Además, durante todo el proceso de las obras, se realizan actividades de información, concientización, difusión y capacitación, las que tienen por objeto permitir el exitoso desarrollo de los proyectos, favorecer la integración de los usuarios al servicio, fomentar el cuidado de los recursos hídricos y del medio ambiente, así como el uso responsable del servicio.

Fundamentalmente, se apuesta a la participación y educación de estos usuarios, para favorecer el mejoramiento de su calidad de vida.

Esto se ve propiciado por la creación de ámbitos de intercambio y mediante la vinculación institucional con asociaciones vecinales, sociedades de fomento e instituciones educativas y sanitarias. En este sentido, es importante resaltar el rol que cumplen los líderes sociales en los temas vinculados a la información y capacitación.

Por otra parte, también se realiza una gestión conjunta con los actores involucrados para adaptar procesos y procedimientos comerciales, técnicos, regulatorios y administrativos, adecuándolos a las necesidades específicas de estos usuarios.

Y este es solo un caso que pone de manifiesto el rol estratégico de la comunicación y plantea los nuevos desafíos que se le presentan a los profesionales del área.

\section{Notas}

1. Área de la concesión de AySA: Ciudad de Buenos Aires, Tigre, San Fernando, San Isidro, Vicente López, San Martín, Tres de Febrero, Morón, Hurlingham, Ituzaingó, La Matanza, Ezeiza, Esteban Echeverría, Alte. Brown, Lanús, Lomas de Zamora, Avellaneda, Quilmes.

\section{Bibliografía}

Cadavid Bringe, A.(2006). Congreso Mundial de Comunicación para el desarrollo ¿Qué comunicación para cuál desarrollo? Colombia: Centro de Competencia en Comunicación para América Latina. 


\begin{abstract}
Summary: In this article the author shares a case leader developed by the water service company supplier in Argentina, within the framework of the management of Social corporate Responsibility in whom a new concept in the professional management of the communication is introduced: CfD - Communication for Development, in a context in which the society is realizing that language 'builds the world'. Also, it reflects about the work of the communication professionals that is no longer to elaborate the appropriate messages and to communicate them of attractive way. The professionals must have the vision and the capacity to generate shared meaning and to cause a process of dialogue, negotiation and consensus with the public, on the base of a double way communication that gives the answers expected by society.
\end{abstract}

Key words: communication for the development - communication management - Community Relations - Corporate Communication - Corporate Image - Corporate Reputation - Corporate Social Responsibility - Digital Communication - Dircom - Institutional Communication - public - Public relations - Social Media.

Resumo: Neste artigo a autora compartilha um caso líder desenvolvido pela empresa provedora em Argentina de um serviço básico e social como é a água, no marco da gestão de Responsabilidade Social Empresária na cual se introduz um novo conceito na gestão profissional da comunicação: $\mathrm{CpD}$ - comunicação para o desenvolvimento- num contexto em que a sociedade vai pegando consciência de que a linguagem constrói o mundo. Alem disso, reflexiona sobre a tarefa dos comunicadores que já não é só elaborar mensagens adequados e comunicar-os de modo atrativo. Os profissionais têm que ter a visão e a capacidade de gerar `significados comuns'e favorecer um processo de diálogo, negociação e consenso com os públicos, sobre a base duma comunicação de dupla via que dêem respostas ao que a sociedade e os diferentes grupos esperam.

Palavras chave: Comunicação Corporativa - Comunicação Digital - Comunicação Empresária - Comunicação Institucional - comunicação para o desenvolvimento - Consumo Inteligente Dircom - gestão comunicacional - Imagem Corporativa - organização - públicos - Relações com a comunidade - Relações institucionais - Relações públicas - Reputação Corporativa Social Media.

(*) Periodista y Licenciada en Psicología Social. [Ver CV completo en la página 155] 